\author{
국내 유우 (Holstein)의 단태 또는 쌍태분만 후 태반정체와 \\ 제4위전위증 발생우의 수태 관련성에 대한 조사 \\ 조진행 · 김명철* · 정성목 · 이재연 · 신범준 \\ 충남대학교 수의과대학
}

(접수: 2012년 4월 21일, 수정: 2012년 6월 26일, 게재승인: 2012년 6월 28일)

\title{
Survey on fertility of retained placenta and abomasal displacement cows after single or twin births in dairy cows in Korea
}

\author{
Jin-Haeng Cho, Myung-Cheol Kim*, Seong-Mok Jeong, Jae-Yeon Lee, Beom-Jun Shin \\ College of Veterinary Medicine, Chungnam National University, Daejeon 305-764, Korea \\ (Received: April 21, 2012; Revised: June 26, 2012; Accepted: June 28, 2012)
}

\begin{abstract}
Calving records of Holstein dairy cows from 2005 to 2010 comprising Goyang and Paju cities herd with 2,362 calving events representing 240 twin births were used to evaluate the effect of abomasal displacement and retained placenta after single or twin births on fertility. In retained placenta cows, the period of twin pregnancy (mean 270.5 days) was shorter than that of single pregnancy (mean 274.8 days), however first artificial insemination period (twin: mean 107.4 days, single: mean 92.0 days), non-pregnant period (twin: 154.8 days, single: 132.2 days), and number of insemination (twin: mean 2.00 times, single: mean 1.87 times) of twin pregnancy were increased as compared with single pregnancy. In abomasal displacement cows, first artificial insemination period (twin: mean 122.9 days, single: mean 106.0 days), non-pregnant period (twin: 172.4 days, single: 152.0 days), and number of insemination (twin: mean 2.16 times, single: mean 1.89 times) of twin pregnancy were increased as compared with single pregnancy. The prevalence of complication such as retained placenta, abomasal displacement with single or twin births increased first artificial insemination period, non-pregnant period, and number of insemination period.
\end{abstract}

Keywords : abomasal displacement, first artificial insemination day, period of pregnancy, retained placenta, twin birth

서 론

유우(dairy cow)의 관리에서 임신 시기의 관리, 즉 적 당한 분만간격의 관리는 경제적인 측면에서 매우 중요 하다. 유우의 번식관리에서 12 13개월로 분만간격을 유 지하고 건유기를 최소화하는 것이 가장 이상적이다 [25]. 분만간격에 영향을 미치는 요인에는 발정기의 감지 능 력, 공태기간, 수태 당 평균 수정횟수가 있다. 100 140 일의 공태기, 평균 1.3 1.7회의 수태 당 수정횟수를 통 해 12 13개월로 분만간격을 유지할 수 있다 [17].

이러한 수태율에 영향을 미치는 요인들은 이전에 재 고된 바 있으며, 기후와 환경, 사육 환경(herd)의 특징, 사육 환경의 관리 및 유우의 특징과 연관성을 갖는다
[6]. 임신기 혹은 임신 전후의 유우의 질병 상태 또한 번 식에 큰 영향을 미칠 수 있으며 대표적인 예로 난산, 사 산, 유산, 유열, 쌍태임신, 태반정체, 자궁내막염, 케톤증 등이 있다 $[11,28]$.

태반정체(retained placenta)는 문헌에 따라 다소 차이 를 보이지만 보통 출산 후 12 시간 이내에 태반이 외부 로 배출되지 않는 질병을 의미한다. 한 보고에 의하면 7,387 증례 중 $10.3 \%$ 의 발병률을 보이며 산차가 증가할 수록 발병률이 증가하는 것으로 알려져 있다 [12, 24]. 태반정체에 영향을 미칠 수 있는 요인에는 유산, 난산, 나이, 영양상태, 임신기간, 스테로이드제의 투여 등이 있 으며 쌍태분만 또한 원인이 될 수 있다 [26]. 수태율에 관한 태반정체의 영향은 몇몇 보고에서는 영향을 미치

\footnotetext{
*Corresponding author

Tel: +82-42-821-6757, Fax: +82-42-821-8903

E-mail: mckim@cnu.ac.kr
} 
지 않는다고 [22] 하지만, 대부분의 보고에 의하면 수태 율을 저하시키고 생식기계의 손상에 의해 번식 기간을 단축시키는 것으로 알려져 있다 [8].

제4위전위증은 왼쪽전위증(left displacement of the abomasum), 오른쪽전위증(right displacement of the abomasum), 오른쪽꼬임전위증(right torsion of the abomasum)으로 분류할 수 있고, 4 위의 부피 및 위치 변 화 능력과 관련되어 있다. 이는 분만 후 먹이의 급격한 변화, 운동감소, 저칼슘혈증, 케톤증, 지방간과 유방염, 태반정체, 유산 및 자궁염(위장운동을 억압하고 4위에 가스를 축적되게 할 가능성이 있는 요인)에 의해 유발 될 수 있다 [15]. 또한 일부 연구에서는 쌍태분만과 큰 체격의 어미소를 위험요인으로 지목하였는데, 이는 그 러한 요인이 4 위가 왼쪽으로 전위될 수 있는 공간을 증 가시키기 때문이다 [5].

쌍태임신은 유우의 종자, 산차 수, 계절 및 우유 생산 능력에 의해 영향을 받으며 [2], 쌍태임신 발생율은 약 $2 \%$ 로 보고되었다 [4]. 쌍태임신은 난산과 공태기간의 증 가를 유발함으로써 직접적으로 수태율에 영향을 미칠 뿐만 아니라, 태반정체 및 4위 전위증을 유발함으로써 간접적으로도 영향을 미칠 수 있다 [23].

따라서 본 연구에서는 수의 진료에 참고가 될 기초자 료를 확립할 목적으로 국내 유우를 대상으로 쌍태분만 의 수태율에 대한 영향을 조사하였으며, 더불어 국내에 서 출산 후 많은 발생을 보이고 있는 태반정체와 제4위 전위증의 수태율에 대한 영향을 단태와 쌍태로 분류하 여 조사하였다.

\section{재료 및 방법}

\section{실험동물}

본 실험에서 사용된 실험동물은 경기도 고양시와 파 주시의 목장에서 사육 중인 유우(Holstein) 70개 목장, 총 2,362두(2 12연령) 를 대상으로 조사하였다.

\section{조사 기간}

단태 또는 쌍태 분만 후 태반정체와 제4위전위증 발 생우의 수태에 대 한 조사를 2005년부터 2010년까지 6 년간 조사하였다(Table 1).

\section{실험 방법}

매월 2회(15일 간격)로 실시하는 정기 검진 시와 축 주 요청에 의한 임상 진료 시에 임상수의사 1 명이 직장 검사를 실시하였으며, 조기 임신 감정은 수정 후 $45 \pm 5$ 일에 단태 및 쌍태임신 감정을 하였고, 건유기 감정은 중자궁 동맥의 촉진으로 태아의 생사를 간접 확인하였 다. 그리고 분만 후에 쌍태아 확인을 실시하였다.

단태와 쌍태 임신우에서의 임신기간, 첫 수정일 및 공 태기간을 구분하여 조사하였다.

쌍태분만 후 태반정체, 제4위전위증, 그리고 태반정체 와 제4위전위증이 동시병발한 우의 경우를 구분하여 각 각 단태분만 후와 비교하였으며, 임신기간, 첫 수정일 및 공태기간을 구분하여 아래의 기준으로 조사하였다. 공 태: 임신하지 않은 성숙한 암컷의 상태, 공태기간: 이전 분만 후 다음 수정까지 소요되는 기간, 태반정체: 태아 태반을 포함한 태막의 일부 또는 전부가 모체외로 배출 되지 않고 자궁내에 정체되어 있는 상태, 제 4 위전위증: 제 4 위의 일부가 본래 있던 자리에서 제 1 위 좌측으로 빠 져 나와서 제 1 위와 복벽 사이에 끼어들거나 또는 우측 으로 이전하여 간과 복벽 사이에 끼어들어서 위치변화 를 일으키고 압박을 받는 상태.

\section{통계 분석}

측정자료의 통계는 평균(mean)과 Pearson의 표준편차 (standard deviation) 계산법을 사용하였으며, 처리간의 유 의성 검정은 $X^{2}$-test를 실시하였다.

\section{결 과}

\section{정상우의 임신기간과 수정}

임신기간은 단태분만우는 평균 278.5 일, 쌍태분만우 는 평균 273.2일로서유의적인 차이는 보이지 않았지만, 쌍태분만우가 평균 5.3일 짧았다. 분만 후 첫수정일은 단태분만우는 평균 87.2일, 쌍태분만우는 평균 95.0일 이었고, 공태기간은 단태분만우는 평균 122.7 일, 쌍태분 만우는 평균 136.7 일로서, 쌍태분만우에서 지연되었다. 수정횟수는 단태분만우는 평균 1.70 회, 쌍태분만우는 평 균 1.76회로 나타났다(Table 2).

Table 1. The distribution of retained placenta and abomasal displacement of cows after single or twin labor

\begin{tabular}{ccccc}
\hline \hline & \multicolumn{4}{c}{ Status of cows after previous labor } \\
\hline Single & Normal & Retained placenta & Abomasal displacement & Combined $^{*}$ \\
Twin & 1,486 & 268 & 339 & 29 \\
& 142 & 67 & 19 & 12 \\
\hline
\end{tabular}

*Retained placenta \& Abomasal displacement. 
Table 2. Fertility in normal cows after single or twin labor

\begin{tabular}{cccccc}
\hline \hline Type of birth & No. of survey & $\begin{array}{c}\text { Gestation period } \\
\text { (days) }\end{array}$ & $\begin{array}{c}\text { First A.I. period } \\
\text { (days) }\end{array}$ & $\begin{array}{c}\text { Non-pregnancy period } \\
\text { (days) }\end{array}$ & $\begin{array}{c}\text { Time of } \\
\text { A.I. }\end{array}$ \\
\hline Single & 1,486 & $278.5 \pm 8.1$ & $87.2 \pm 36.7$ & $122.7 \pm 57.5$ & $1.70 \pm 1.0$ \\
Twin & 142 & $273.2 \pm 7.5$ & $95.0 \pm 40.2$ & $136.7 \pm 57.8$ & $1.76 \pm 1.6$ \\
\hline
\end{tabular}

${ }^{*}$ A.I.: artificial insemination.

Table 3. Fertility in retained placenta cows after single or twin labor

\begin{tabular}{cccccc}
\hline \hline Type of birth & No. of survey & $\begin{array}{c}\text { Gestation period } \\
\text { (days) }\end{array}$ & $\begin{array}{c}\text { First A.I. period } \\
\text { (days) }\end{array}$ & $\begin{array}{c}\text { Non-pregnancy period } \\
\text { (days) }\end{array}$ & Time of A.I. \\
\hline Single & 268 & $274.8 \pm 16.9$ & $92.0 \pm 43.2$ & $132.2 \pm 59.4$ & $1.87 \pm 1.2$ \\
Twin & 67 & $270.5 \pm 9.6$ & $107.4 \pm 49.0$ & $154.8 \pm 65.6$ & $2.00 \pm 1.2$ \\
\hline
\end{tabular}

Table 4. Fertility in abomasal displacement cows after single or twin labor

\begin{tabular}{ccccc}
\hline \hline Type of birth & No. of survey & $\begin{array}{c}\text { First A.I. } \\
\text { period (days) }\end{array}$ & Non-pregnancy period (days) & Time of A.I. \\
\hline Single & 339 & $106.0 \pm 42.4$ & $152.0 \pm 66.1$ & $1.89 \pm 1.2$ \\
Twin & 19 & $122.9 \pm 34.6$ & $172.4 \pm 63.3$ & $2.16 \pm 1.6$ \\
\hline
\end{tabular}

Table 5. Fertility in retained placenta and abomasal displacement cows after single or twin labor

\begin{tabular}{ccccc}
\hline \hline Type of birth & No. of survey & First A.I. period (days) & Non-pregnancy period (days) & Time of A.I. \\
\hline Single & 29 & $114.2 \pm 46.0$ & $167.2 \pm 75.0$ & $2.21 \pm 1.3$ \\
Twin & 12 & $147.1 \pm 80.5$ & $176.8 \pm 70.8$ & $2.33 \pm 1.8$ \\
\hline
\end{tabular}

\section{태반정체우의 수정과 임신기간}

임신기간은 단태분만우는 평균 274.8 일, 쌍태분만우는 평균 270.5 일로서 공태기간은 유의적인 차이는 보이지 않았지만, 쌍태분만우가 평균 4.3일 정도 짧았다. 분만 후 첫수정일은 단태분만우는 평균 92.0일, 쌍태분만우는 평균 107.4일이었으며, 단태분만우는 평균 132.2일, 쌍태 분만우는 평균 154.8 일로서, 쌍태분만우에서 지연되었 다. 수정횟수는 단태분만우는 평균 1.87회, 쌍태분만우 는 평균 2.00 회로 나타났다(Table 3 ).

\section{제4위전위증우의 수정과 임신}

분만 후 제 4 위전위증우의 경우 첫수정일은 단태분만 우는 평균 106.0 일, 쌍태분만우는 평균 122.9 일로서 유 의적인 차이는 보이지 않았지만, 쌍태분만우에서 지연 을 나타내었다. 공태기간은 단태분만우는 평균 152.0 일, 쌍태분만우는 평균 172.4 일로서, 쌍태분만우에서 지연되 었다. 수정횟수는 단태분만우는 평균 1.89회, 쌍태분만 우는 평균 2.16회로 나타났다(Table 4).

\section{태반정체와 제 4 위전위증 병발우의 수정과 임신}

분만 후 태반정체와 제 4 위전위증 병발우의 경우 첫수 정일은 단태분만우는 평균 114.2 일, 쌍태분만우는 평균 147.1 일로서, 유의적인 차이는 보이지 않았지만, 쌍태분 만우에서 지연을 나타내었다. 공태기간은 단태분만우는 평균 167.2일, 쌍태분만우는 평균 176.8 일로서 쌍태분 만우에서 지연되었다. 수정횟수는 단태분만우는 평균 2.21회, 쌍태분만우는 평균 2.33회로 나타났다(Table 5).

\section{고 찰}

국내 유우의 관리에 있어 번식과 산유량의 증가는 경 제적 이익과 직접적으로 관련되어있다. 이 중 번식은 새 끼소를 얻는 측면에서도 중요하지만 산유량에도 영향을 미치기 때문에, 여러 관리 방법이 제시되고 있다. 그 중 에서 질병이 번식에 미치는 영향은 이미 재고된 바 있 다 [13].

본 연구에서는 국내 경기도 지역에서의 쌍태임신은 평균 $3.9 \%$ 의 발생율을 보이는 것으로 조사되었다. 쌍태 
로 인해 산유량이 증가했다는 보고와 [30] 산유량이 감 소했다는 [19] 보고가 모두 있어서, 쌍태와 산유량의 상 관관계는 단순하게 판단할 문제가 아니라고 사료된다. 그러나 쌍태가 번식관리에는 부정적인 영향을 끼친다고 볼 수 있는데, 쌍태임신에 의한 난산이외에도 여러가지 악영향들이 알려져 있기 때문이며, 이 중 난산이 발생하 는 이유로는, 태아 크기 증가에 의한 경우와 태위 위치 변화에 의한 경우로 분류할 수 있다 [20]. 쌍태분만이 제 4 위전위증 및 케톤증과 같은 대사성 질병을 야기할 수 있다는 측면도 간과해서는 안 된다 [14].

유우에서의 임신기간은 전체 태아의 크기와 반비례하 는 것으로 알려져 있다. 즉 태아의 크기가 클수록 임신 기간은 짧아지게 된다. 쌍태임신의 경우 단태 임신에 비 해 전체적인 태아의 크기가 크기 때문에 임신 기간이 짧 아지게 되며, 보통 단태에 비해 3 6일 정도 조산하는 것 으로 알려져 있다 [29]. 이번 조사에서도 쌍태의 경우 평 균 273일의 임신기간으로 단태의 평균 278 일에 비해 평 균 5일 정도 조산하는 것으로 밝혀졌으며, 또한 이전 태 반정체우의 경우에서도 단태와 쌍태 각각 평균 275 일과 평균 271일로 쌍태임신의 경우 평균 4일 정도 조산하는 것으로 조사되었다. 이외에도 태아 폐사, 난산, 태반정체 의 확률 증가 및 프리마틴 발생확률의 증가, 공태 기간 의 증가는 번식관리에 있어 단점으로 작용할 수 있다 [3]. 공태기간은 분만후부터 다음 임신까지 소요되는 기간 이다. 공태기간이 증가하면 도태율이 증가하고 유량이 감소하며, 사육비용이 증가하고 도태에 따른 대체 비용 이 발생하기 때문에, 경제적 손실이 발생한다 [7]. 이전 연구에 따르면 쌍태분만우가 단태분만우보다 약 12 22 일 가량 공태기간이 더 긴 것으로 보고되었다 [16]. 본 조사에서는 쌍태분만우가 단태분만우보다 공태기간이 평균 14 일 더 긴 것으로 나타났다. 공태기간은 자발적 공태기간(voluntary waiting period, VWP), 발정의 인식, 수태율과 같은 인자에 의해 영향을 받는데, 이러한 인자 들 때문에 각 연구마다 공태기간의 차이가 발생하는 것 으로 사료된다.

공태기간은 분만 후 생리 주기와도 밀접한 관련이 있 고, 한 보고에 의하면 쌍태임신우의 경우 분만 후 자궁 퇴축의 지연, 난소 기능 회복 지연 및 난포난소기의 증 가가 발생할 수 있으며, 이러한 요인은 공태기간의 증가 를 초래할 수 있다. 이번 조사에서도 첫수정일이 단태분 만우가 평균 87.2 일인 것에 비해 쌍태분만우는 평균 95.0 일로 더 길게 연장된 것이 확인되었다.

이번 조사에 의하면 평균 수정횟수가 단태분만우는 평균 1.70 회, 쌍태분만우는 평균 1.76 회로, 수태율이 떨 어지는 것이 확인되었다. 이는 이전 Kay [19]와 BenDavid [1]에 의해 보고된 것과 일치하는 것으로, 쌍태분
만 후 자궁내막염 발생율의 증가와 난소 기능 회복 지 연에 의한 것으로 사료된다.

산유량과 번식 관리를 이상적으로 유지하기 위해서는 번식 간격을 최소화해야 하고, 번식 간격을 최소화하려 면 분만 후 자궁퇴축과 난소기능회복이 필수적인 요소 이다.

태반정체는 분만 후 12 시간 이내 태반이 모우로부터 배출되지 않는 질병으로 정의되며, 이는 임상적, 무증상 적으로 자궁내막염을 유발할 수 있다. 자궁내막염은 불 임 및 임신 지연을 일으키는 흔한 원인으로 주로 E. coli 와 Arcanobacterium pyogen이 자궁 손상과 염증을 유발 한다. 또한 분만 후 발정 주기의 발현을 지연시키고 황 체기를 지연시킴으로써 임신율을 떨어뜨릴 수 있는 것 으로 알려져 있다 [27]. 이번 조사에서도 정상 단태분만 우에서 첫수정일이 평균 87.2 일인 것에 비해, 태반정체 우의 경우는 평균 92.0 일로 지연되었으며, 쌍태분만우에 서 첫수정일이 평균 95.0 일인 것에 비해, 태반정체우는 평균 107.4 일이었다. 이는 앞서 설명한 자궁내막염의 발 생으로 인한 자궁 손상 및 발정 주기 발현의 지연과 관 련되는 것으로 사료된다. 또한 자궁내막염으로 인해 수 정횟수도 증가한 것으로 생각된다 (정상우: 평균 1.70 회, 태반정체우: 평균 1.87회). 즉, 태반정체로 인해 자궁 내막염이 생겨서 첫수정일과 수정횟수가 늘어나고, 결 국 공태기간이 늘어나는 것이다.

제4위전위증의 번식에 관한 영향에는 상반된 의견이 많다. Eicker 등 [9]과 Erb 등 [10]에 의하면 많은 개체 에서 조사하였을 때 제4위전위증 자체적으로는 번식에 영향을 미치지 않는 것으로 보고되어 있다. 그러나 제 4 위전위증은 고능력우에서 발생률이 높은 질환으로 케톤 증, 저칼슘혈증과 같은 대사성 질환과 큰 연관성을 갖는 다. Harman 등 [18]과 Lindstrom 등 [21]은 케톤증에 의 해 번식 능력이 떨어질 수 있다고 보고하였다. 이러한 연구들을 토대로 제4위전위증의 번식에 관한 직접적인 연관성은 알 수 없지만 간접적인 영향으로 인해 번식 능 력이 떨어질 수 있다는 것을 생각해 볼 수 있다.

본 연구에서 제 4 위전위증에서 첫수정일은, 단태분만 우 평균 106.0 일 \& 쌍태분만우 평균 122.9 일이며, 공태 기간일은 단태분만우 평균 152.0 일, 쌍태분만우 평균 172.4 일이었고, 수정횟수는 단태분만우 평균 1.89회, 쌍 태분만우 평균 2.16회로 나타났다. 즉, 단태와 쌍태 모 두에서 제 4 위전위증우의 첫수정일, 공태기간, 수정횟수 가 증가한 것으로 나타났다. 본 연구에서도 제4위전위 증우가 태반정체우보다도 첫수정일, 공태기간, 수정횟수 모두에서 더 증가된 것으로 나타났으므로, 제4위전위증 이 번식과 밀접한 관련이 있다고 사료된다. 앞으로 제4 위전위증의 직접적인 영향에 대해서는 보다 자세한 연 
구가 필요할 것이다.

태반정체와 제 4 위전위증 동시 발병우에 대한 보고는 찾기가 매우 힘들었다. 이번 연구에서 첫수정일은 단태 분만우 평균 114.2일, 쌍태분만우 평균 147.1일이었고, 공태기간일은 단태분만우 평균 167.2 일, 쌍태분만우 평 균 176.8 일이었으며, 수정횟수는 단태분만우 평균 2.21 회, 쌍태분만우 평균 2.33회였다. 즉, 단태와 쌍태 모두 에서 태반정체와 제4위전위증 동시 발병우의 첫수정일, 공태기간, 수정횟수가 증가한 것으로 나타났다.

본 조사의 자료를 기초로해서 생각해보면 단태분만우 에 비해 쌍태분만우, 또한 단태와 쌍태 모두에서 태반정 체우, 제4위전위증우, 태반정체와 제4위전위증 병발우에 서 분만 후 첫수정일, 공태기간일, 수정횟수가 모두 증 가한 것으로 나타났다. 즉 쌍태, 태반정체, 제 4 위전위증, 태반정체와 제 4 위전위증 병발시 각각 독립적으로 수태 율에 악영향을 끼친다는 것을 확인할 수 있었다.

또한 이 세가지 요인이 결합될 경우에는 더욱 더 수 태율에 악영향을 끼친다는 것도 확인할 수 있었다. 공태 기간을 기준으로 하면, 각각의 요인들이 공태기간을 지 연시킬 때보다 병합되었을 때에 더 많이 지연되었다. 즉 쌍태, 태반정체, 제4위전위증은 공태기간 지연에 상승 효과를 보이는 것이다(쌍태 14.0일, 태반정체 9.5일, 제 4 위전위증 29.3 일, 태반정체 \& 제4위전위증 44.5 일, 쌍태 \& 태반정체 32.1 일, 쌍태 \& 제 4 위전위증 49.7일, 태반정 체 \& 제 4 위전위증 44.5 일, 쌍태 \& 태반정체 \& 제 4 위전 위증 54.1일).

이상의 결과를 종합하여 볼 때, 본 연구로 국내에서 사육중인 유우에 있어서, 쌍태분만, 태반정체 그리고 제 4 위전위증이 다음 번식에 부정적인 영향을 미치는 것을 확인하였다. 이로써 대한 수의 임상 분야에 참고가 될 기초 자료가 확립되었다고 생각하며, 이를 바탕으로 추 가적인 연구가 진행되길 기대한다.

결론적으로, 2005년부터 2010년까지 6년간에 걸쳐 경 기도 고양시 및 파주시 일원의 목장에서 사육중인 임신 유우 2,362 두를 대상으로 다음과 같은 결론을 얻었다. 자연분만한 쌍태분만우는 단태분만우보다 임신기간이 5.3 일 짧았으며, 첫수정일(7.8일), 공태기간(14.0일) 및 수 정횟수(0.06회) 모두 지연되었다. 태반정체우의 경우에 는 임신기간이 자연 분만우에 비해 단태는 3.7 일, 쌍태 는 8.0일 짧았으며, 그 후 첫수정일(단태: 4.8 일, 쌍태: 20.2일), 공태기간(단태: 9.5일, 쌍태: 32.1일) 및 수정횟 수(단태: 0.17회, 쌍태: 0.3회) 모두 지연되었다. 제4위전 위증의 경우에는 자연분만우에 비해 첫수정일(단태: 18.8 일, 쌍태: 35.7일), 공태기간(단태: 29.3일, 쌍태: 49.7일) 및 수정횟수(단태: 0.19회, 쌍태: 약 0.46회) 모두 지연되 었다. 태반정체와 제4위전위증이 동시병발한 우의 경우
에는 자연 분만우에 비해 첫수정일(단태: 27.0 일, 쌍태: 59.9 일), 공태기간(단태: 44.5일, 쌍태: 54.1일) 및 수정횟 수(단태: 0.51회, 쌍태: 0.63회) 모두 지연되어 경제적 손 실, 유량의 감소 및 사양관리에 불리한 조건을 유발하였 다. 본 연구에서 나타난 바와 같이 단태 및 쌍태분만우 에서 태반정체우, 제4위 전위증, 그리고 태반정체와 제 4위전위증을 동시병발한 우인 경우 임신 기간, 첫수정 일, 공태기간 및 수정횟수가 모두 지연되었다는 결론을 확인하였으므로, 이에 대한 개선책을 제시할 수 있는 연 구가 앞으로 더욱더 진행되길 기대한다.

\section{감사의 글}

이 논문은 2010년도 정부(교육과학기술부)의 재원으 로 한국연구재단의 지원을 받아 수행된 기초연구사업임 (No.2010-0024553).

\section{참고문헌}

1. Ben-David B. Twin birth in cows. Refu Vet 1982, 39, 67.

2. Cady RA, Van Vleck LD. Factors affecting twinning and effects of twinning in Holstein dairy cattle. J Anim Sci 1978, 46, 950-956.

3. Chapin CA, Van Vleck LD. Effects of twinning on lactation and days open in Holsteins. J Dairy Sci 1980, 63, 1881-1886.

4. Cho CH. Theriogenology. pp. 329-330, Youngjae Gyoyukwon, Seoul, 1981.

5. Constable PD, Miller GY, Hoffsis GF, Hull BL, Rings DM. Risk factors for abomasal volvulus and left abomasal displacement in cattle. Am J Vet Res 1992, 53, 1184-1192.

6. de Kruif A, Brand A. Factors influencing the reproductive capacity of a dairy herd. N Z Vet J 1978, 178, 183-189.

7. de Vries A. Economics of delayed replacement when cow performance is seasonal. J Dairy Sci 2004, 87, 2947-2958.

8. Dyrendahl I, Mattson J, Pehrson B. Retained placenta in cattle -- incidence, clinical data and effects on fertility. Zentralbl Veterinarmed A 1977, 24, 529541.

9. Eicker SW, Gröhn YT, Hertl JA. The association between cumulative milk yield, days open, and days to first breeding in New York Holstein cows. J Dairy Sci 1996, 79, 235-241. 
10. Erb HN, Martin SW, Ison N, Swaminathan S. Interrelationships between production and reproductive diseases in holstein cows. Path analysis. J Dairy Sci 1981, 64, 282-289.

11. Erb HN, Smith RD. The effects of periparturient events on breeding performance of dairy cows. Vet Clin North Am Food Anim Pract 1987, 3, 501-511.

12. Erb RE, Hinze PM, Gildow EM, Morrison RA. Retained fetal membranes: the effect on prolificacy of dairy cattle. J Am Vet Med Assoc 1958, 133, 489-496.

13. Fourichon C, Seegers H, Malher X. Effect of disease on reproduction in the dairy cow: a meta-analysis. Theriogenology 2000, 53, 1729-1759.

14. Fricke PM. Review: twinning in dairy cattle. Prof Anim Sci 2001, 17, 61-67.

15. Fubini SL, Ducharme NG. Farm Animal Surgery. 1st ed. pp. 173-300, Elsevier, St. Louis, 2004.

16. Guerra-Martinez P, Dickerson GE, Anderson GB, Green RD. Embryo-transfer twinning and performance efficiency in beef production. J Anim Sci 1990, 68, 4039-4050.

17. Hafez ESE, Hafez B. Reproduction in Farm Animals. 7th ed. pp. 337-345, Williams \& Wilkins, Philadelphia, 2000.

18. Harman JL, Gröhn YT, Erb HN, Casella G. Eventtime analysis of the effect of season of parturition, parity, and concurrent disease on parturition-toconception interval in dairy cows. Am J Vet Res 1996, 57, 640-645.

19. Kay RM. Changes in milk production, fertility and calf mortality associated with retained placentae or the birth of twins. Vet Rec 1978, 102, 477-479.

20. Kirkpatrick BW. Management of twinning cow herds.
J Anim Sci 2002, 80, E14-18.

21. Lindstrom UB, Von Bonsdorff M, Syvajarvi J. Factors affecting bovine ketosis and its association with non-return rate. J Sci Soc Finland 1983, 55, 497-507.

22. Muller LD, Owens MJ. Factors associated with the incidence of retained placentas. J Dairy Sci 1974, 57, 725-728.

23. Nielen M, Schukken YH, Scholl DT, Wilbrink HJ, Brand A. Twinning in dairy cattle: A study of risk factors and effects. Theriogenology 1989, 32, 845-862.

24. Roberts SJ. Veterinary Obstetrics and Genital Disease (Theriogenology). 2nd ed. pp. 317-336, Edwards Bros, Ann Arbor, 1971.

25. Sakaguchi M. Practical aspects of the fertility of dairy cattle. J Reprod Dev 2011, 57, 17-33.

26. Sandals WCD, Curtis RA, Cote JF, Martin SW. The effect of retained placenta and metritis complex on reproductive performance in dairy cattle -- a case control study. Can Vet J 1979, 20, 131-135.

27. Sheldon IM, Price SB, Cronin J, Gilbert RO, Gadsby JE. Mechanisms of infertility associated with clinical and subclinical endometritis in high producing dairy cattle. Reprod Domest Anim 2009, 44 (Suppl 3), 1-9.

28. Stevenson JS, Call EP. Reproductive disorders in the periparturient dairy cow. J Dairy Sci 1988, 71, 25722583.

29. Thorburn GD, Challis JR, Currie WB. Control of parturition in domestic animals. Biol Reprod 1977, 16, 18-27.

30. Wood PDP. A note on the effect of twin births on production in the subsequent lactation. Anim Prod 1975, 20, 421-424. 